\title{
Javier Rodríguez Weber, Desarrollo y desigualdad en Chile (1850-2009). Historia de su economía política. Santiago, Chile. Centro de Investigaciones Diego Barros Arana, 2017.
}

\author{
Mario Matus G."
}

21 de junio de 2017

$\mathrm{P}$ Rimordialmente, debo felicitar al Centro de Investigaciones Diego Barros Arana, perteneciente a la Dirección de Bibliotecas, Archivos y Museos de Chile por la iniciativa de publicar este libro que, sin duda, será una aportación sustantiva al conocimiento de la evolución histórica de la desigualdad en Chile. Esta publicación culmina una investigación que tuve el privilegio de conocer desde sus primeros esbozos y puedo decir con propiedad que fui testigo de su progreso a lo largo de los años. Del mismo modo, he observado como el autor robusteció los resultados de su tesis de magister para convertirla en tesis doctoral, a la vez que hacía otras indagaciones, que si bien no fueron incorporadas en estas etapas anteriores se integraron en gran medida en este libro.

En ese sentido, me dedicaré esencialmente a evaluar este trabajo en su dimensión como trabajo de historia económica. Al respecto, quisiera llamar la atención sobre algunos rasgos que me parecen dignos de destacar.

En primer lugar, al tratarse de una reconstrucción histórica de la desigualdad en Chile, que abarca casi la totalidad de su trayectoria independiente, ha supuesto un esfuerzo gigantesco en materia de recolección de datos. Cualquiera que se haya enfrentado a la magna tarea de construir series temporales largas sabrá que para arribar a un gráfico que sintetice la evolución de una variable económica durante varias décadas debe invertirse una enorme cantidad de tiempo, hurgando -muchas veces infructuosamente- entre diversas fuentes para tejer lentamente una trama de datos. Tarea que resulta titánica cuando se trata de cubrir periodos en que la era estadística daba sus primeros pasos y, por lo tanto, las fuentes son

*Académico y Director del Dpto. de Cs. Históricas. Universidad de Chile. 
esquivas, miserables o francamente decepcionantes, y en que los valores deben ser sometidos a todo tipo de test para constatar su fiabilidad y representatividad. Posteriormente, cuando ya se cuenta con ciertos tramos relativamente cubiertos, los datos deben procesarse rigurosamente para que sean homologables y no se generen distorsiones artificiales. Luego, siempre surge la necesidad de plantearse ciertas interpolaciones -aunque sean mínimas- para completar las series. Por cierto, el problema se complica cuando hay tramos largos de una serie ya extensa construidos con distintas metodologías, como ocurre con un imposible empalme entre la última tabla social dinámica que utiliza el autor y la Encuesta de Ocupación y Desocupación del Gran Santiago, realizada por la Universidad de Chile, así como la Encuesta de Caracterización Socioeconómica Nacional de Chile (CASEN), realizada por el Ministerio de Desarrollo Social de Chile. Finalmente, los datos ya homologados en una unidad común deben ser revisados varias veces y sus trayectorias deben ser contrastadas con las mejores alternativas disponibles. Así es como Javier Rodríguez llega a ese dichoso gráfico 5 (p. 87), que muestra nada menos que casi toda la trayectoria histórica de la desigualdad de ingreso en el Chile Republicano, que más de uno insertará en una presentación de power point, sin saber todos los desvelos y sacrificios que ha requerido.

Por otra parte, y buscando acertadamente que su trabajo pudiera ser leído con mayor facilidad por un público relativamente amplio, y no sólo por especialistas, el autor ha optado por no incluir todo el volumen de datos utilizados ni la composición de cada una de las tablas que subyacen a su trabajo. A sabiendas que esa decisión es legítima y justificada, recomendaría que en el futuro el Centro de Investigaciones Diego Barros Arana pueda publicar esa información basal en un volumen de fuentes, a fin de que cualquier investigador pueda replicar, contrastar y utilizarla para múltiples fines la valiosa información cuantitativa que subyace a este trabajo. Sin duda, generaciones de historiadores e investigadores en ciencias sociales lo agradecerán enormemente.

En paralelo, esa labor de construcción también ha supuesto superar innumerables dilemas metodológicos que en mi opinión ha resuelto del mejor modo, apelando a las mejores técnicas disponibles. En efecto, para este tipo de estudios la elección del método de tablas sociales dinámicas presenta ventajas muy superiores a otras posibles formas de acercamiento y es la fórmula de mayor rigor metodológico que nos permite pensar - hasta que se descubran eventualmente fuentes más ricas- que no es posible por ahora acceder a una medición más confiable de la desigualdad en Chile a lo largo de su historia.

Pero el rigor en la construcción de los datos me permite destacar otro aspecto de esta obra. En ningún momento el autor incurre en el error de sobreestimar sus hallazgos. Si bien es cierto, defiende y justifica apropiadamente sus procedimientos constructivos, continuamente está advirtiendo del alcance de sus resultados, que adecuadamente define como tendencias robustas de mediano y 
largo plazos, además previene de la tentación de pensar que la misma altura que muestra el coeficiente de Gini en Chile en 1910 y en 1988 pudiera remotamente significar que en ambos años se alcanzó el mismo nivel de desigualdad. Se trata de un ejercicio de honestidad intelectual y de proporcionalidad que siempre debe guiar un trabajo historiográfico.

Pero además de este aspecto, lo que hace que este trabajo sea un magnífico ejemplo de una investigación en historia económica es que, por un lado, expresa un dominio muy avanzado en técnicas de construcción estadística, sin las cuales una aproximación seria a la desigualdad devendría especulativa o, en el mejor de los casos, estaría basada en valoraciones bien intencionadas pero subjetivas. Por otro lado, se trata de una obra que está muy lejos de caer en lo que llamaría un "misticismo cuantitativista", que se caracteriza por atribuir un rasgo de superioridad a ese tipo de información, y que desprecia en consecuencia, la contrastación que siempre debe hacerse con información de tipo cualitativa o con otras dinámicas cuantitativas con las que debiera guardar cierta concordancia.

Debo también destacar la cautela y el buen olfato con que Javier Rodríguez logra moverse dentro de un complejo entorno teórico. Como todo buen historiador, el autor recela de patrones universales que atribuyan en todo tiempo y lugar las trayectorias de la desigualdad a factores unívocos. Pero no se queda en eso, puesto que su defensa de la historicidad -es decir, de la causalidad compleja de los fenómenos dentro de un juego de fuerzas cambiantes- se materializa plenamente cuando procede a probar que ni una fase expansiva basada en bienes primarios conlleva necesariamente a una elevación en el nivel de desigualdad, ni una fase contractiva generada por una caída de la demanda externa necesariamente genera una caída en la desigualdad al contraerse el ingreso del decil más elevado. Siguiendo esa lógica, el trabajo de Rodríguez también demuestra que no toda intervención del Estado y no todo proceso de expansión democrática necesariamente garantizan un decaimiento de la desigualdad, ya sea porque el Estado puede estar al servicio de intereses oligárquicos o de una minoría -como ocurrió hasta 1920 y volvió a suceder durante la Dictadura de Pinochet- o debido a que gobiernos bien intencionados -como el de la Unidad Popular- no lograron darle sostenibilidad macroeconómica ni política a sus políticas redistributivas.

Precisamente, la habilidad con que Javier Rodríguez se mueve entre mecanismos de mercado y tesis neoinstitucionalistas constituye uno de los mayores aportes del trabajo, porque aunque no intenta restarle méritos a cada una de estos enfoques, sí sabe usarlos dosificadamente y de modo ecléctico, siempre pesquisando cómo se combinaron dentro de la historicidad de cada etapa. Por eso, también me parece apropiado el rescate que el autor hace de Kuznets de manos de sus divulgadores "vulgares", como diría Marx. Porque efectivamente ¿no fue Kuznets quien dijo que todos los países, dentro de una lógica evolucionista lineal -como la que planteaba Rostow- debían pasar por una primera etapa de elevado 
crecimiento y desigualdad, para luego seguir creciendo con una desigualdad en declive? Lo único que probaron los estudios de Kuznets es que un número muy acotado de países y en un periodo temporal muy acotado vivió ese tipo de trade-off entre crecimiento y desigualdad. Y de hecho, lo que correspondía científicamente era estudiar qué combinación específica de relaciones de poder, reglas de juego (instituciones) y fuerzas económicas influyentes generaron la primera y la segunda fase. Denostar a Kuznets, porque ningún país de América Latina ha mostrado nunca una $U$ invertida, implica arrojar al niño con el agua sucia, ya que en realidad -y siguiendo a Branko Milanovic- la lógica de la curva de Kuznets nos permite advertir que actualmente las economías desarrolladas se encuentran en proceso de una segunda fase de empeoramiento, pero sin llegar a asomarse ni siquiera remotamente una segunda fase de caída de la desigualdad. La teoría económica, como la sociológica, politológica, demográfica, antropológica o psicológica, siempre debe ser usada prudentemente y con mucha cautela, porque se trata de construcciones que están concebidas para sugerir preguntas interesantes, pero tienden a reducir y a empobrecer las posibilidades de explicación historiográfica, por lo que siempre deben ser contrastadas por la experiencia concreta de las sociedades, ese laboratorio social conformado por la Historia de los hombres y las mujeres. Y todo esto tiene mucha utilidad para no caer en disputas que son absurdas desde su inicio, como la de si la desigualdad se inició en el siglo XIX en América Latina o si ya era elevada durante los tres siglos coloniales, cuando sabemos que no podemos comparar niveles de desigualdad que en un caso se expresan a través del ingreso y en el otro en dimensiones jurídicas, raciales o culturales, es decir, esencialmente no económicas. Y de esto se cuida muy bien esta obra.

Lo anterior no significa que el autor no logre distinguir dinámicas dominantes de otras subordinadas, porque tampoco incurre en el otro extremo, de un escepticismo relativista, desafortunadamente tan en boga por corrientes intelectuales influidas por un deconstructivismo extremo. En efecto, y pasando al contraste de sus tendencias de desigualdad a mediano y largo plazos con otras dinámicas económicas, pero también políticas, sociales y acaso culturales, el autor logra dotar de fiabilidad cada movimiento importante a través de su respectivo encadenamiento e inserción dentro de una trama histórica. No es poco, porque incluso si no estuviéramos totalmente convencidos de la coherencia que muestra su entrecruzamiento de trayectorias, nos entrega los hilos que podemos profundizar, contrastar y verificar. Por eso es que la obra también puede ser leída como un yacimiento cruzado por múltiples vetas, donde cada una de ellas abre una puerta a distintas agendas de investigación a un sinnúmero de investigadores. Desde mi perspectiva, estas tendencias de la desigualdad tienen sentido y coherencia, dentro del juego de variables que las acompañan y con las que contraen relaciones de afinidad y complementariedad. Por cierto, dan al traste con la suposición inveterada de que los niveles de desigualdad de ingreso han ostentando siempre el mismo 
nivel en Chile. Pero también explican de manera sensata la trama de factores que en cada periodo originaron fases de empeoramiento, de reducción significativa o de relativo estancamiento de este tipo de desigualdad en Chile entre 1850 y 2009. Esto no significa, en ningún caso, que nuevas investigaciones no puedan enmendar y refinar algunos movimientos o ciertos niveles, pero no me extrañaría que las trayectorias de largo plazo que esta obra ha develado y apoyado con contundencia -usando las mejores fuentes y técnicas disponibles hasta ahora- se queden grabadas por un largo tiempo, no sólo en los estrechos círculos universitarios, sino también en espacios más amplios.

Esto me lleva a una última reflexión: la pertinencia y contemporaneidad de esta obra, su posible alcance dentro y fuera de Chile y de qué modo sus potencialidades emanan de su mismo origen. Normalmente este tipo de obras son áridas, debido a que descansan en un enorme esfuerzo constructivo que el autor debe desplegar en su totalidad para que su fuerza explicativa demuestre estar apoyada en fundamentos robustos. Del mismo modo, y como bien lo señala el autor, los trabajos que se dedican a la desigualdad tratan de revestirse exageradamente de una falsa asepsia, para que no vayan a ser descalificados como frutos de un posicionamiento ideológico que las contamina.

El autor ha sido consciente de estas aprehensiones, pero ello no le ha imposibilitado plantearse una aproximación que sabe será polémica y generará debate. Y así actúa porque lo hace desde la honestidad de un historiador que hace una Historia de la Desigualdad en Chile -que habría sido el mejor título para esta obra-, confiado en que ha llevado al límite sus capacidades como investigador, preocupado por dotar a su trabajo de rigor científico, pero también consciente de ser un testigo externo, beneficiado por un mayor grado de independencia y de experiencias comparables, como advertido de los tiempos que se viven en Chile, América Latina y el mundo. Tiempos en que se requiere aproximaciones, que por nunca estar totalmente libres de posicionamientos ideológicos, deben ser templadas por un estricto y exigente instrumental metodológico y deben estar apoyadas en un voluminoso aparato documental, que en el caso de los historiadores económicos son cifras que deben resistir muchos embates, deben ser contrastadas por otro tipo de información y deben quedar disponibles para superar las pruebas de falsabilidad.

Al terminar estas líneas debo reconocer que esta magnífica obra me ha recordado por qué quise dedicarme a la historia económica y lo importante que puede ser su aporte para una sociedad como la chilena, actualmente congestionada por la sensación de vivir en crisis, que probablemente no sea más que una nueva crisis de crecimiento, que ciertamente requiere de respuestas nuevas. Respuestas que tienen que ver con la nueva larga duración que estamos viviendo y que comenzó a inicios de la década de 1990, en el mundo y en Chile. Es cierto que aunque esta obra ilumina una vasta zona que hasta ahora había estado oscura, no permite resolverlo todo, básicamente porque conocer los factores cambiantes que 
han generado ciertas tendencias en la desigualdad del ingreso en el largo plazo nos retiene dentro de un ámbito de problemas que tiene que ver con la proyección de políticas de demanda, pero no nos señala los caminos que deberíamos tomar para propiciar políticas de oferta que generen un cambio estructural. Esencialmente porque eso es tarea de una política con mayúsculas. Personalmente, creo que estos hallazgos sirven poco para elaborar un cambio gradual y acumulativo en términos de reconversión productiva y, por cierto, no se puede pretender que sean una fórmula garantizada para sostener elevadas tasas de crecimiento. Pero lo que está fuera de toda duda es que entregan una visión panorámica que es fundamental para diseñar y ejecutar políticas redistributivas. Pero además sugieren que no vale la pena sostener un modelo de crecimiento que a estas alturas sólo ofrece un elevado nivel de desigualdad, pero que -por su agotamiento evidente- ya no es capaz de garantizar una tasa elevada y sostenida de crecimiento. ¿Significa esto que hay que refundar por completo el país? En absoluto. Podemos combinar lo mejor de los aprendizajes realizados para responder de modo equilibrado a los desafíos futuros. Y en esto, el trabajo de Rodríguez es un precioso regalo, porque entrega algunas claves imprescindibles para replantearnos los principales desafíos que tenemos como sociedades latinoamericanas. 